\title{
Study Regarding the Transmissibility Vibrations about Hand-Arm System, Using Vibration Attenuation
}

\author{
CRISTEA Aurora Felicia ${ }^{1, a}$ \\ ${ }^{1}$ Technical University of Cluj-Napoca, Buildings of Machines Faculty, Mechanical Systems \\ Engineering Department, 400641, B-dul Muncii, no. 103-105, Cluj-Napoca, Romania
}

ae-mail: cristea_fa@yahoo.de

Key words: Hand-arm system, Vibration attenuator, Professional affections

\begin{abstract}
The aim of the paper is to present a way to reduce mechanical vibrations that are transmitted to the operator's arm at workplace. This can be done using an innovative device, a damper mounted parallel to the forearm, between the wrist and the elbow.

The innovative idea of this paper is the creation (design and realization of the practice) of a vibration attenuator device, which will be mounted along of the forearm; this could minimize the transmitted vibration, by the hand up the arm.

The simulation demonstrated that there is a way to reduce the mechanical vibrations for the hand-arm system model chosen. This could lead to the reduction of occupational illnesses that are frequently found in workplaces like this.

The conclusions of the experiment performed validated the theoretical results generated by the simulation and have shown that, by using an attenuator device mounted parallel to the forearm (between the wrist and the elbow), we can reduce vibrations along the arm to the shoulder by $50 \%$.
\end{abstract}

\section{Introduction}

The subject of this paper has as starting point the analysis of the measurements of mechanical vibrations transmitted from a machine-tool to the human operator. It was observed that transmitting vibrations, at low frequencies, in this paper around $20 \mathrm{~Hz}$, at the causes negative effects on the individual's health, respectively professionally diseases (for example Vibration White Finger, joint disorders, etc). I was found that, these disorders are especially associated to the intensity of the vibrations the individual is subjected to, i.e. the duration of the exposure and their frequency. Apart from the exposure and their frequency, there are other factors that influence the occurrence of these disorders, such as: the environment, the health status, stature, weight and sex [1-5].

When talking about transmitting mechanical vibrations to the hand-arm system, the literature mentions protective equipment against the transmission of mechanical vibrations to the hand, namely gloves manufactured from various materials (rubber, linen, combinations of these, etc.), there are of course, other protection measures against the transmission of mechanical vibrations to the hand-arm system. Some of the vibratory devices are manufactured with parts meant to protect the operator against vibrations. The protective measures refer to the design of the machine with incorporated attenuators, and the ergonomic construction of such vibratory tools and devices. Sometimes, the construction material is the one that facilitates the vibration reduction (such as rubber) [1, 2]. This paper however focuses on the first part, namely protective gear against the transmission of vibrations to the hand-arm system, which is being mounted on.

In our country, in the period 1992-2011, the professional diseases due to work increased. From this perspective, the most affected from the occupational point of view were: locksmiths, miners, smelters, foundry-workers, welders, medical assistants, carpenters and mechanics workers (Fig. 1, Fig. 2). 
The figures 1 and 2 present a comparison of professional disorders on trade categories, noticing that locksmiths occupy the top of the list. On the other hand, the transmission of mechanical vibrations is the number one cause or professional disorders in our country.

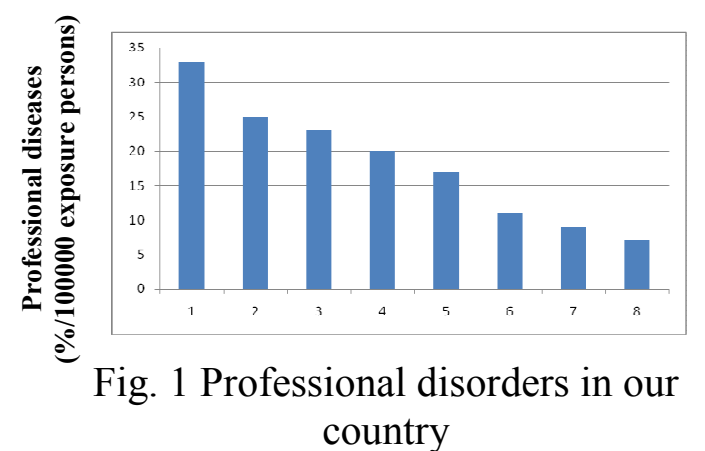
country

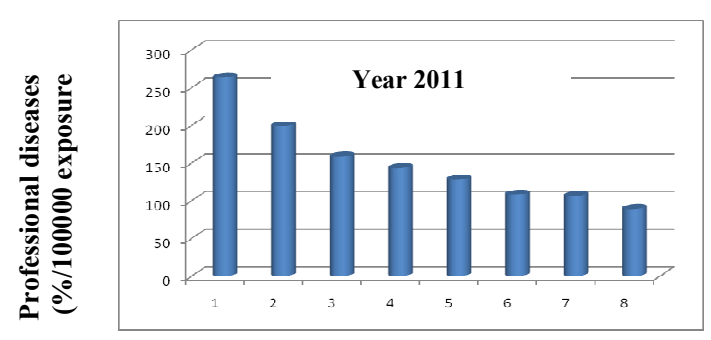

Fig. 2 The new cases apparition of professional diseases in 2011.

Mentioning the gloves again, when using these during the operating various vibrating machines, the grip is not very strong, the vibrations are transmitted and dissipated through the gloves and thus the vibrations are reduced by the time they reach the elbow. Wearing gloves in vibrating environments that are dangerous for the arm is mandatory by norms and standards. But the disadvantages can be a random factor: because through gloves one cannot control the grip and therefore many people avoid wearing them because:

They do not allow optimal dexterity, since the tactile sense is suppressed almost entirely. The literature mentions especially the protection given by the way in which tools and machines are produced. This is why this study deals with mounting an attenuator device on the hand-arm system (parallel to the forearm), which is regarded as a most welcome protective device. Simulations have proven that wearing such an attenuator device can reduce the vibrations transmitted to the arm along the arm and to the shoulder and thus reducing the risk of occupational illnesses on this particular segment.

Another positive aspect about wearing such a protection device is the fact that the tactile sense is restored in the fingers and palm in connection to grabbing tools and devices.

\section{Simulation study}

Simulation of the Movements of the Hand-Arm System (on the Anatomic Elements: Hand, Forearm and Arm) Not Using/Using a Vibration Attenuator Device

In the order of simulation of movements defining the anatomical elements (hand, forearm, arm) of the hand-arm system, using the same simplifying conditions used as in the mechanical model from figure 3, as the same mechanical parameters (viscous-elastic coefficients), masses, lengths, etc., two methods developed in Simulink-SimMechanics [3, 4, 6, 16 and 17]. This way, the two models (schemes) developed in SimMechanics: one representing a hand-arm model without vibration attenuator and the second having this attenuator mounted on the forearm shall be presented in the figures 4 and 5 .

The results obtained by simulation of the hand-arm system displacements (linear and angular displacements) [8-10] are graphically represented by Scope Blocks in SimMechanics. Respectively, for the hand $\left(\mathrm{z}_{1}\right)$ displacement, for the forearm $\left(\mathrm{z}_{2}\right)$ displacement, for the arm displacements $\left(\mathrm{x}_{3}, \mathrm{z}_{3}\right)$, and rotation $\left(\Theta_{3}\right)$ for the $\mathrm{Oy}_{\mathrm{h}}$ - angular displacement produced in the elbow joint. 
Tab.1 Initial simplifying conditions

\begin{tabular}{|l|l|}
\hline Direction of excitation & $\mathrm{Z}_{\mathrm{h}}$ (along of the forearm) \\
\hline Excitation & Harmonic displacement $z(t)=z_{0} \sin \omega t$ \\
\hline Position of the subject & Standing (vertical position) \\
\hline Frequency scale & $0-20 \mathrm{~Hz}$ \\
\hline Force of pressure of the tool & $25 \mathrm{~N}$, according to ISO 15230/2007 \\
\hline Place of pressure & Hand (palm and fingers) \\
\hline
\end{tabular}

Tab. 2 Anthropometrical parameters

\begin{tabular}{|l|l|l|}
\hline \multicolumn{3}{|c|}{ Anthropometrical parameters } \\
\cline { 1 - 2 } $\mathrm{m}_{1}=0.45 \mathrm{~kg}$ & $\mathrm{l}_{3}^{\prime}=0,298 \mathrm{~m}$ & $\mathrm{~J}_{\mathrm{c} 3}=0.0149 \mathrm{kgm}^{2}$ \\
\hline $\mathrm{m}_{2}=1.15 \mathrm{~kg}$ & $1_{3}=0.178 \mathrm{~m}$ & \\
\cline { 1 - 2 } $\mathrm{m}_{3}=1.9 \mathrm{~kg}$ & $1_{3} / 1_{3}^{\prime}=0,6$ & \\
\hline
\end{tabular}

Table 3 Visco-elastic coefficients of hand-arm system, under the conditions imposed by table 1

\begin{tabular}{|c|c|c|c|}
\hline \multicolumn{4}{|c|}{ Viscous-elastic parameters of the hand-arm system } \\
\hline $\mathrm{k}_{0}=155.8 \times 10^{3} \quad \mathrm{~N} / \mathrm{m}[7]$ & \multirow[b]{2}{*}{$\mathrm{k}_{\mathrm{t} 1}=2 \mathrm{Nm} / \mathrm{rad}[7]$} & $\mathrm{c}_{0}=30 \quad \mathrm{Ns} / \mathrm{m}[7]$ & \multirow[b]{2}{*}{$\mathrm{c}_{\mathrm{t} 1}=4,9 \mathrm{Nms} / \mathrm{rad}[7]$} \\
\hline $\mathrm{k}_{1}=23.6 \times 10^{3} \mathrm{~N} / \mathrm{m}[7]$ & & $\mathrm{c}_{1}=202.8 \mathrm{Ns} / \mathrm{m} \mathrm{[7]}$ & \\
\hline $\mathrm{k}_{2}=444.6 \times 10^{3} \quad \mathrm{~N} / \mathrm{m}[7]$ & $\mathrm{k}_{\mathrm{t} 2}=2 \mathrm{Nm} / \mathrm{rad}[7]$ & $\mathrm{c}_{2}=500 \quad \mathrm{Ns} / \mathrm{m}[7]$ & $\mathrm{c}_{\mathrm{t} 2}=6,14 \mathrm{Nms} / \mathrm{rad}[7]$ \\
\hline $\mathrm{k}_{3}=415.4 \times 10^{3} \mathrm{~N} / \mathrm{m}[7]$ & & $\mathrm{c}_{3}=164.6 \mathrm{Ns} / \mathrm{m} \mathrm{[7]}$ & \\
\hline $\mathrm{k}_{4}=50.25 \times 10^{3} \quad \mathrm{~N} / \mathrm{m}[7]$ & & $\mathrm{c}_{4}=50 \quad \mathrm{Ns} / \mathrm{m}[7]$ & \\
\hline $\begin{array}{c}\mathrm{k}^{\prime}=2 \mathrm{k}^{\mathrm{d}}=2 \times 365.75=731.5 \\
\mathrm{~N} / \mathrm{m}\end{array}$ & & $c^{\prime}=2 c^{d}=2 \times 58.5=117$ & \\
\hline
\end{tabular}

The solutions obtained [11-17] are the result of the integration of a differential equations system through the SimMechanics (Simulink) module using the 4th order Runge-Kutta method (ODE 45), and an integration period of 5s (Fig. 6, and Fig. 7).

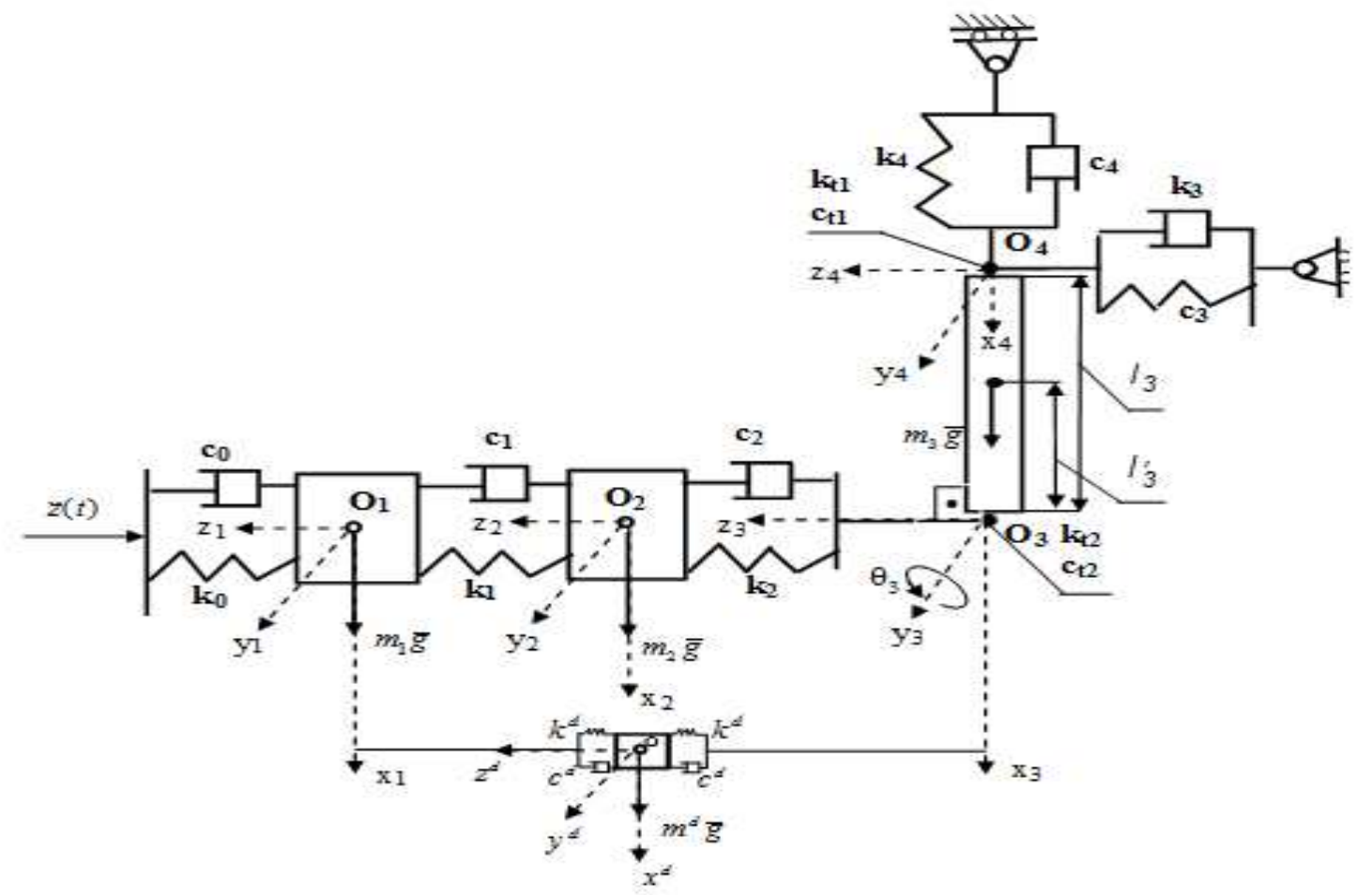

Fig. 3 Mechanical hand-arm system. (Model with 6 degrees of freedom $-z_{1}, z_{2}, z_{3}, z^{d}, x_{3}, \theta_{3}$ ); Montage on the forearm of a vibration attenuator (where: $c^{\prime}=2 c^{d} ; k^{\prime}=2 k^{d}$ ). 
Table 4 - The main Simulink Blocks presented in the figures 4 and 5.

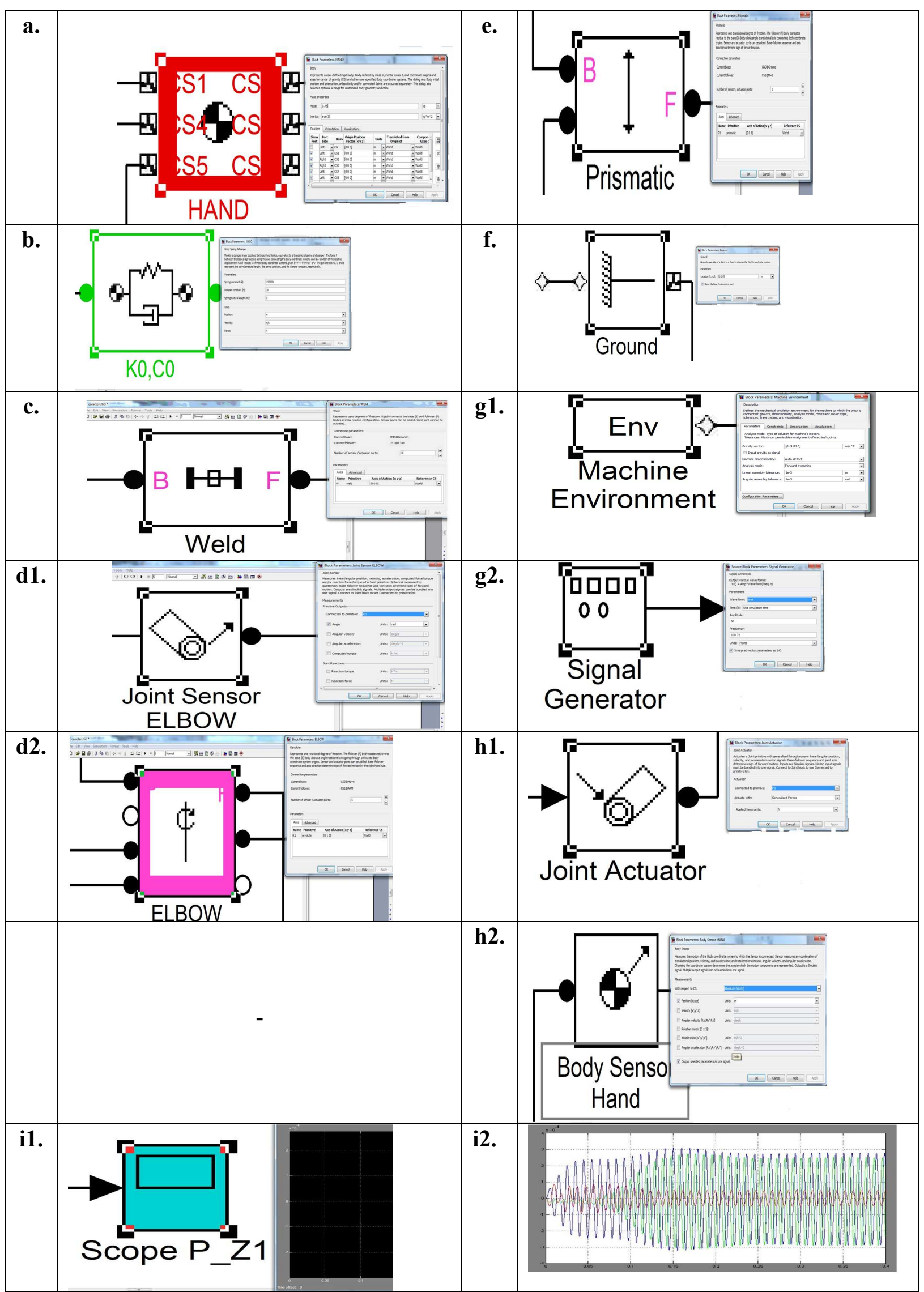


For this paper it chose the Matlab simulation program (its Simulink), because this presents a friendly interface and, more importantly, has blocks (Table 4) that display the mechanical point of view for the system masses Mass Block (a.), the mechanical characteristics (Elastic and Damping Block - b.), the connecting blocks that can copy the mechanical model in figure 3, respectively Weld Blocks (c.) and Cylindrical Joints (Joint elbow and Shoulder Block d1. and d2.). Also, it presents blocks that allow setting the displacement or rotation direction of the system as a Prismatic Block (e.). In other words, the connection between the blocks creates the same model as the theoretical model resulted from the mathematical modeling. Also, it can intervene in this system by imposing entry conditions that is $z$ and the input frequency or pulse given by the Ground Block(f.), Machine Environment Block and Signal Generator (g1. and g2.).

By accessing any of these blocks, a window opens in which it can input the mechanical theoretical model characteristics given by figure 3. Subsequently, this model will simulate the displacements of the system created by Simulink. The Joint Actuator Block and Body Sensor Block (h1. and h2.) take over the displacements of the masses and convey it to the Scope Block (i1. and i2.). This displays graphically the displacements of the center of these masses. Main displacement is imposed by the Prismatic Block (e.), which, in the case of this paper, is the $z$-axis that is along the hand-arm system. In this case, the selection of the $x, y, z$ coordinates in the data window will be: $x=0 ; y=0 ; z=1$. It notice that only the elbow joint that is the $\mathrm{m}_{3}$ mass of the arm displacements (displacements of the mass center presented in i2. block) along all three axes. For this reason it select $x=1, y=1$ (displacements given by the angle $\theta_{3}$ ), and $z=1$.

In the figures 4,5 the symbolized blocks, per ensemble, represent:

- Excitation source Block named 1; $\quad$ - Hand (mass $m_{1}$ ) Block named 2;

- Forearm (mass $m_{2}$ ) Block named 3; $\quad$ - Arm (mass $m_{3}$ ) Block named 4;

- Mechanical vibration attenuator $\left(m^{d}\right)$ Block named 5 (Fig. 5).

In the next paragraph will be present the main blocks of the SimMechanics scheme.

Therefore, ensemble 1 contains in SimMechanics the blocks Env and Ground specific for the source of excitation (machine-tool), and the Signal block where it is imposed at simulation the frequency or the excitation pulsation. The source of excitation is considered for this model is at a rotation of $250 \mathrm{rpm}$ - rotations per minute $(\mathrm{f}=4.16 \mathrm{~Hz}$ ) (Fig.6), and respectively at the rotation of 1000rpm ( $\mathrm{f}=16.66 \mathrm{~Hz}$ ) (Fig.7), similar to the theoretical model studied at the mechanical model presented in the figure 3.

The ensembles noted 2, 3, and 4 in the figures $4 \mathrm{a}, 5 \mathrm{a}$ are connected between each other by Prismatic Blocks, blocks that impose the direction of the vibrations transmission, by axis $\mathrm{Oz}_{\mathrm{h}}$, and for the arm it is considered and the direction of transmission after $\mathrm{Ox}_{\mathrm{h}}$.

Equally, ensembles 1, 2, 3, and 4 are connected between each other by Spring and Damper Blocks, representing the blocks where the mechanical characteristic are introduced (rigidity and dampness coefficients) of the hand-arm system, according to Table 2.

Ensembles 2, 3, and 4, and subsequently for the vibration attenuator device ensemble 5 (Fig. 4a and Fig. 5a), comply with the same anthropometric properties from table 3, as in the mechanical model proposed by figure 3, respectively the Body Blocks with the masses $\mathrm{m}_{1}, \mathrm{~m}_{2}, \mathrm{~m}_{3}$ and subsequently $\mathrm{m}_{4}$ for the vibration attenuator device.

The Body Sensor and Scope Blocks are necessary for the visualization of individual solutions, on the anatomic elements: hand, forearm and arm, respectively the visualization of solutions (linear and angular displacements) of the system, obtained in SimMechanics.

In the study of the block scheme, the simplifying conditions imposed by the mechanical model in figure 3 were complied with, so it was considered the rotation in the shoulder joint of $0^{\circ}$, and in SimMechanics this was represented by Weld and Ground Blocks of ensemble 4 (Fig.4), and of ensemble 5 (Fig.5). 


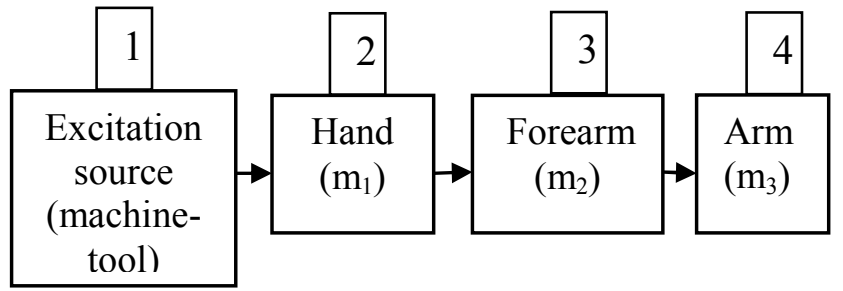

a.

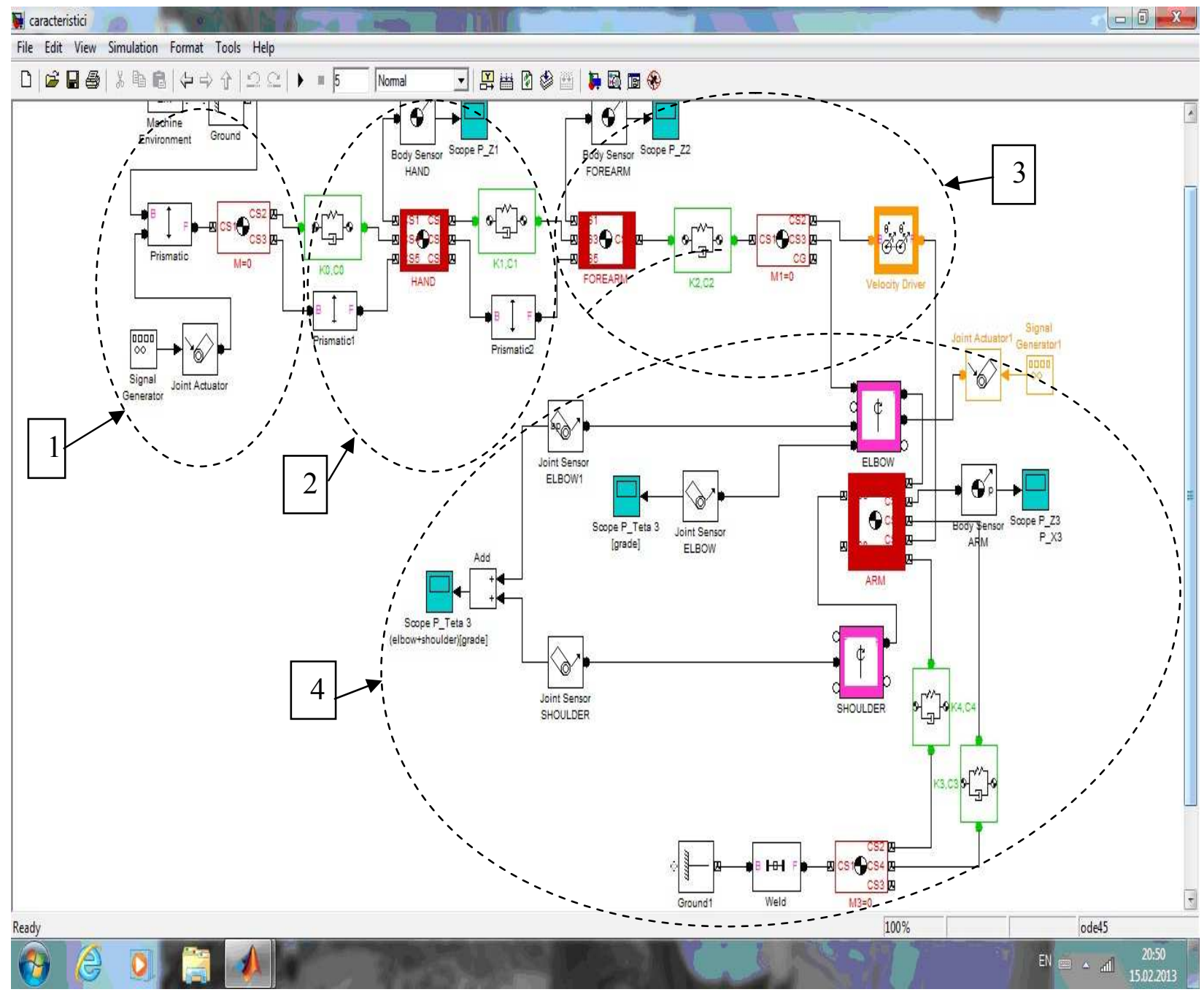

b.

Fig. 4 a. The schematic model, per ensemble, of the hand-arm system;

b. The block scheme of the mechanical model, representing the hand-arm system developed in SimMechanics.

The results obtained, in SimMechanics, were processed and overtaken in Excel, they analyzed comparatively regarding the two cases studied, respectively the hand-arm system without montage of the vibration attenuator device and with the it mounted on the forearm ( Fig.6, Fig.7). 


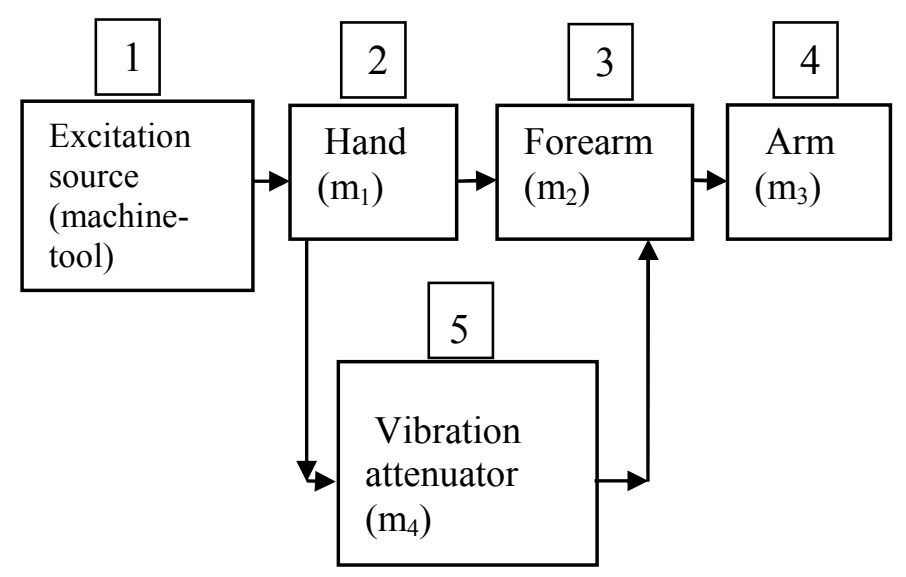

a.

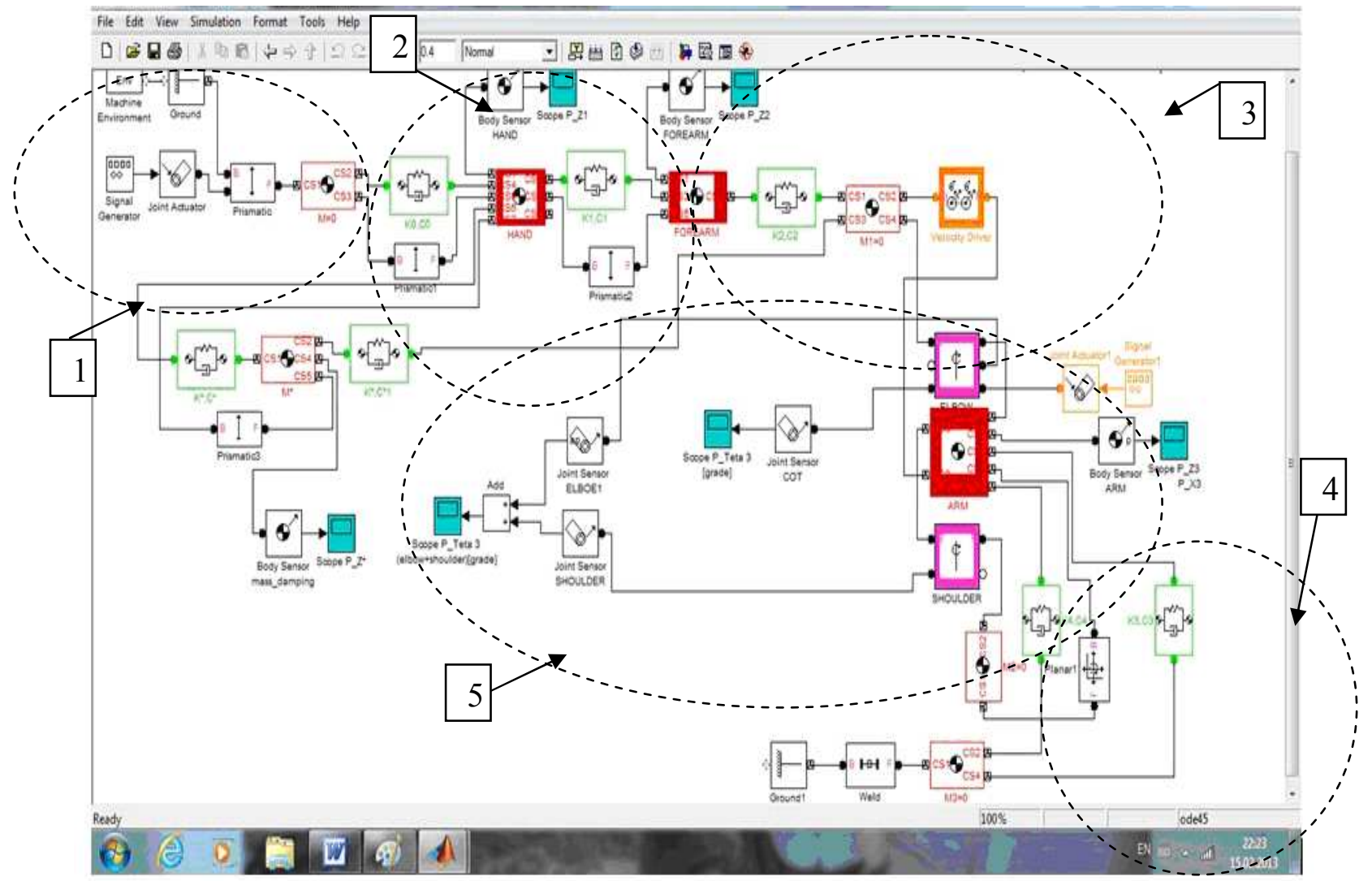

b.

Fig. 5a. The schematic ensemble model of the hand-arm system;

b. The scheme model of the mechanical model representing the hand-arm system, having mounted along the forearm the vibration attenuator developed in SimMechanics.

\section{Analysis of the Solutions Obtained from the Simulation of the Displacements of the Hand-Arm System, Without or With the Vibration Attenuator Device Mounted on the Forearm}

In the figures $6 \mathrm{a}$ and $7 \mathrm{a}$ can be observed the movement of the hand $\left(\mathrm{z}_{1}\right.$ displacement) for the rotation of the machine-tool of $250 \mathrm{rpm}$, is not influenced by montage of the vibration attenuator device along the forearm (Fig.6a) or it is very slightly influenced by this, at the rotation of 1000rpm (Fig.7a). This behaviour might be due to the fact, that the vibration attenuator device is mounted after the joint, this only influencing the transmission of the vibrations from the joint up the forearm and the arm. The $\mathrm{z}_{1}$ displacement takes a maximal value of the graphic (Fig.6a) around $0.003 \mathrm{~m}$. 
Graphically, it can be observed that the vibrations transmitted from the source of excitation (machine-tool) are reduced, in case a mechanic vibration attenuator device mounted on the forearm in used. This displacement is noted in the paper with $\mathrm{z}_{3}$, and it is graphically represented in figures $6 \mathrm{c}$ and $7 \mathrm{c}$.

In the figures $6 \mathrm{~b}$ and $7 \mathrm{~b}$, it can be observed the minimization of the transmission of the vibrations for the forearm and the arm, when a vibration attenuator device is mounted along the forearm is used $\left(\mathrm{z}_{2}\right)$. The values of the $\mathrm{z}_{2}$ displacements for the forearm are minimized from $0.003 \mathrm{~m}$ till $0.002 \mathrm{~m}$ (Fig.6b.) (the revolution of $250 \mathrm{rpm}$ ) and from $0.0025 \mathrm{~m}$ till $0.0008 \mathrm{~m}$ (Fig.7b) (the revolution of 1000rpm).

To these graphics minimization (reduction) of the displacements, it vary from $0.001 \mathrm{~m}$ till $0.0025 \mathrm{~m}(\mathrm{n}=250 \mathrm{rpm})$ (Fig. $6 \mathrm{c})$ and from $0.01 \mathrm{~m}$ till $0.00025 \mathrm{~m}(\mathrm{n}=1000 \mathrm{rpm})$ presented in the figure $7 \mathrm{c}$.

Due to the fact, that in the figures 7 , comparatively with figures 6 , the excitation at the entrance in the hand-arm system is 4 times bigger (from 250rpm till 1000rpm), for the same integration period $(5 s)$, and the frequency of graphical representations of the displacements harmonics are of 4 times bigger.

The results (displacements) obtained are graphical represented in the figures 6 and 7, it showed that the mechanical vibrations transmitted from the source of excitation (machine-tool) till the hand-arm system are minimized along it. Therefore at the arm, respectively elbow joint the vibrations are minimized by over $50 \%$, all these having been proved only in the case of usage of a vibration attenuator device mounted along the forearm.
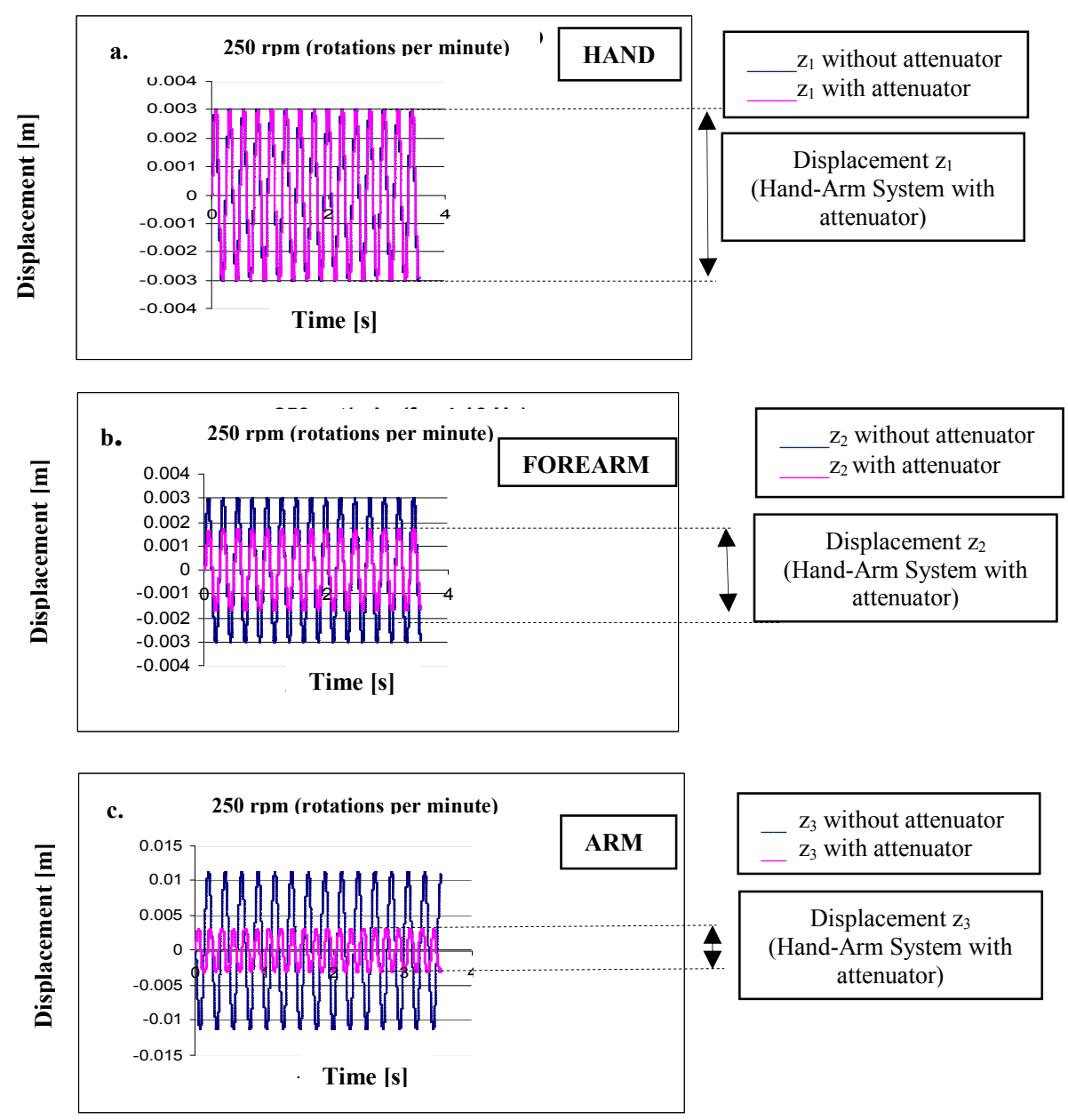

Fig. 6. Transmission of the vibration along the hand-arm system, using a vibration attenuator device (250rpm). a. Displacement of the hand- $\mathrm{z}_{1}[\mathrm{~m}] ; \mathrm{b}$. Displacement of the forearm- $\mathrm{z}_{2}[\mathrm{~m}]$; $\mathrm{c}$.

Displacement of the arm $-\mathrm{z}_{3}[\mathrm{~m}]$. 

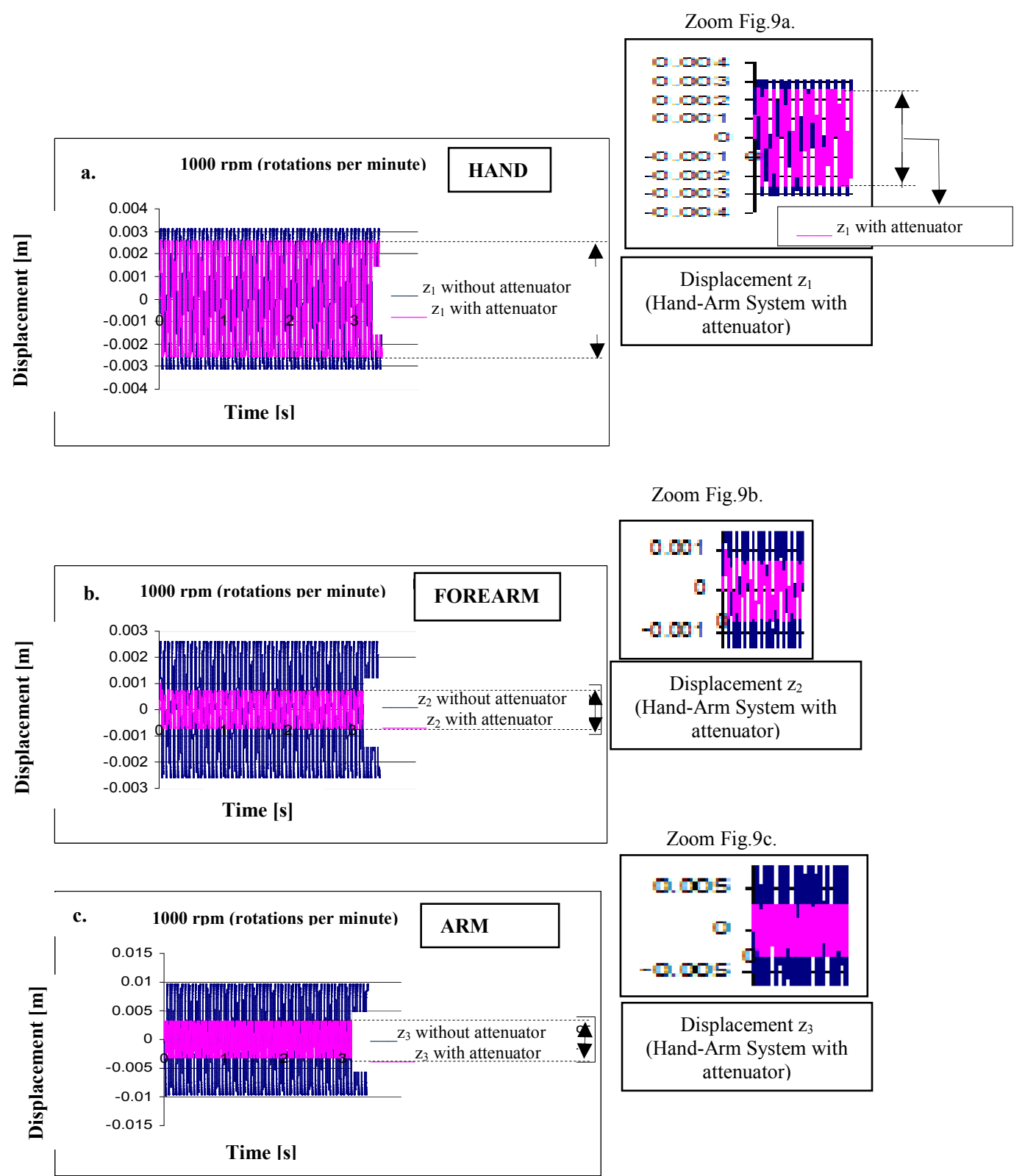

Fig. 7. Transmission of the vibration along the hand-arm system, using a vibration attenuator device $(1000 \mathrm{rpm})$. a .Displacement of the hand- $\mathrm{z}_{1}[\mathrm{~m}] ; \mathrm{b}$. Displacement of the forearm- $\mathrm{z}_{2}[\mathrm{~m}] ; \mathrm{c}$.

Displacement of the arm $-z_{3}[\mathrm{~m}]$.

\section{Experimental Researches}

The researches regarding the transmissibility of mechanical vibrations to the arm-hand system have been performed by measuring the mechanical vibrations using a drilling machine. The machine drilled through a chemically treated MDF board using a $10 \mathrm{~cm}$ drill. The experiment measured the vibrations transmitted by the machine when operating with percussion and without percussion (Fig.8-16).

The innovative idea of this paper is the creation (design and realization of the practice) of a vibration attenuator device, which will be mounted along of the forearm; this could minimize the transmitted vibration, by the hand up the arm (Fig.18b.). The vibration attenuator device (containing 2 dampers) was mounted along the forearm and fixed with a complex shank (bracelets). The damper device was mounted between the wrist and the elbow, parallel to the forearm (Fig. 18b), in accordance to the theoretical model in figure 3, both in terms of the placement and technical characteristics (rigidisation and dampers). Also, the weight of the device is $0,5 \mathrm{~kg}$, just like the theoretical model. 
The figure $18 \mathrm{a}$ and $18 \mathrm{~b}$ presents the way the dampers (element 1) are fixed in the structure. They are connected to each other in the back side of the forearm with a linear and metallic clamping element which has two metallic caps welded at the ends with jaws (element 2). One of the damper ends (the mobile one) is attached to these jaws and the other one (the fixed one) has an external thread and is introduced in the holes of the bracelet (Ф11) (element 3). This fastens the two semicircles on and under the articulation with an M10 nut. The metal bracelets are fixed at the other end of the forearm (above the wrist) with an M5 screw and nut (element 4).

A 40 year old male, weighing $85 \mathrm{~kg}$ and $1.85 \mathrm{~m}$ tall, used and handled the drilling machine. The measurements used an inductive transducer (accelerometer type $\mathrm{K}_{3}$ ), (element 5, and Fig.18a), being able to simultaneously measure vibrations on three axes: $\mathrm{Ox}_{\mathrm{h}}, \mathrm{Oy}_{\mathrm{h}}, \mathrm{Oz}_{\mathrm{h}}$. This was connected to a vibration measuring device type SVAN 958. The study was done only for the vibration transmission on the $\mathrm{Oz}_{\mathrm{h}}$, axis, respectively alongside the forearm of the hand-arm system. The accelerometer was mounted on the anatomic locations: wrist and elbow, being fastened directly under the metallic bracelet by tightening it (Fig. 18) and directly on the arm (taped). The results are analyzed in the figures 8-16 for all the cases taken into account by the experiment and taking into consideration the anatomic location (wrist, elbow and shoulder), the way in which the bracelets were fastened on the skin (sponge - Fig. 18a and felt - Fig. 18b), and whether the drilling machine worked with or without percussion. The interior padding of the metallic bracelets have been done to prevent skin lesions and to prevent blocking the worker's forearm movements.

Next it explicit the way in which the dampers were chosen (two elements marked with 1, in figure $18 \mathrm{a}$, which is mounted in series, parallel to the forearm, in the attenuator device in figure $18 \mathrm{~b}, \mathrm{c})$ according to the technical characteristics in table 5 .

The two dampers are similar from the construction and technical characteristics point of view. This is why we present both as element 1 (Fig.18b,c). They are sold based on their elastic and damping characteristics, given by the damper from the mechanical model presented in figure 3 , that is seeking technical characteristics and masses that are identical or almost identical to the theoretical model. When choosing these mini-dampers it had to take into account the fact that the entire device (including the two mini-dampers mounted in series) had not be heavier than $0.5 \mathrm{~kg}$.

Table 5 - Mini-attenuator of vibration named FA 1008 VB, technical characteristics.

\begin{tabular}{|l|l|}
\hline Technical characteristics & Adequate values \\
\hline Type & Adjustable \\
\hline Displacement & $8 \mathrm{~mm}$ \\
\hline Functional temperature scale & $-5 \mathrm{by} 65^{\circ} \mathrm{C}$ \\
\hline Mass & $0,026 \mathrm{~g}$ \\
& \\
& \\
\hline Field & $0,6-10 \mathrm{Kg}$ \\
\hline Energy capacity & $3,6 \mathrm{kNm} / \mathrm{h}$ \\
\hline Exterior screw dimension & $M 10 x \mathrm{~W}$ \\
\hline Exterior attenuator diameter & $10 \mathrm{~mm}$ \\
\hline External dimensions & $65,5 \mathrm{~mm}$ \\
\hline Transmitted force & $3-6 \mathrm{~N}$ \\
\hline
\end{tabular}

The measured results have been analyzed and an average was calculated. They have been recorded directly by the machine, and then downloaded on the computer using a special program. 


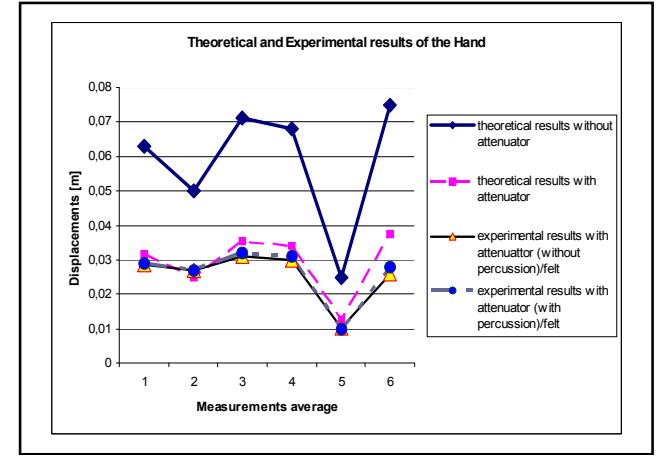

Fig. 8 Vibrations transmitted to the hand (theoretical and experimental) with and without attenuator with felt padding, and using a drilling machine with and without percussion.

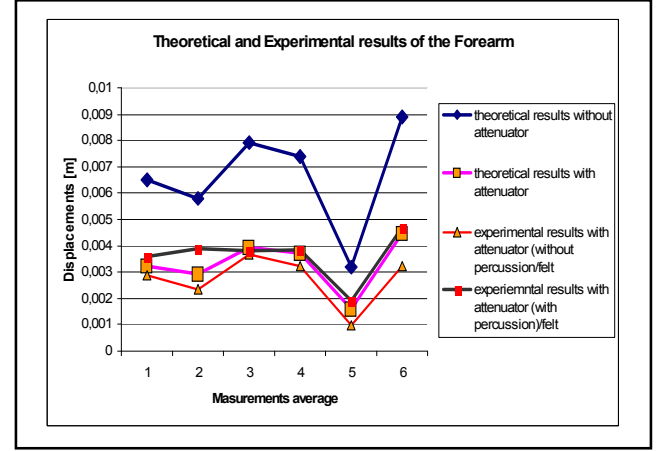

Fig. 9 Vibrations transmitted to the forearm (theoretical and experimental) with and without attenuator with felt padding, and using a drilling machine with and without percussion.

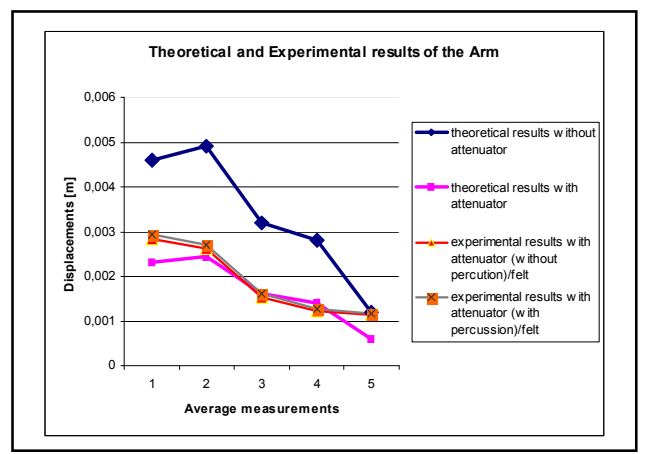

Fig. 10 Vibrations transmitted to the arm (theoretical and experimental) with and without attenuator with felt padding, and using a drilling machine with and without percussion.

The first analysis of the results presented in the figures 8,9 and 10 show that the mechanical vibration are transmitted along the hand-arm system to a lower extent if:

1. a vibration attenuator is mounted along the forearm (starting with 0.07 till $0.03 \mathrm{~m}$ for the hand, 0.08-0.03 for the forearm and 0.005 till 0.0025 for the arm);

2. the percussion of the drilling machine is not used;

3. the internal padding of the bracelets that are part of the attenuator device is done with sponge and not felt.

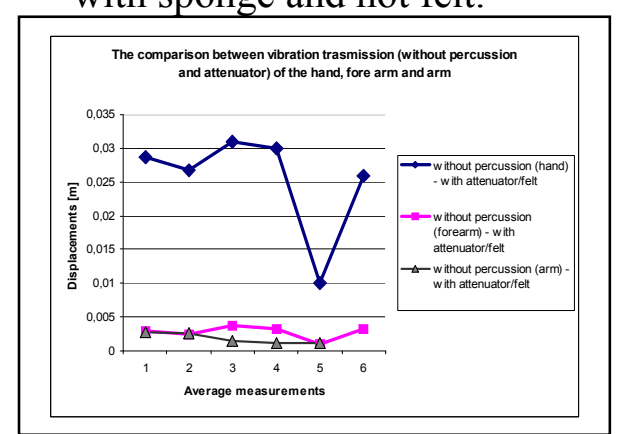

Fig. 11 Vibrations transmitted to the hand, forearm and arm with a vibration attenuator, with felt padding, and using a drilling machine without percussion.

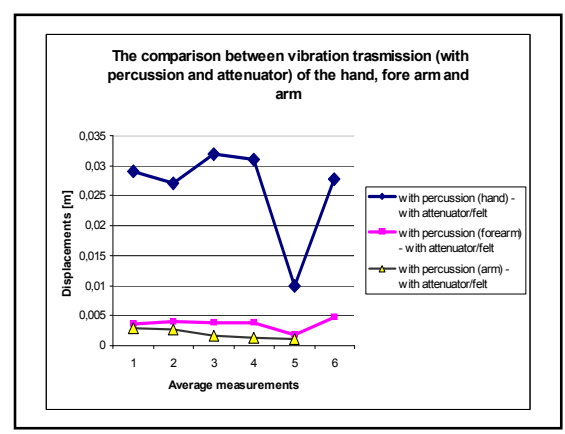

Fig. 12 Vibrations transmitted to the hand, forearm and arm with a vibration attenuator with felt padding, and using a drilling machine with percussion.

The results in figures 11 and 12 show that, by using the drilling machine without and with percussion and a damper with felt padded bracelets, in both cases the vibrations in the three anatomic locations (hand, forearm and arm) are reduced (starting with 0.03 till $0.005 \mathrm{~m}$ ) in the first case (without percussion) in comparison the other case. 


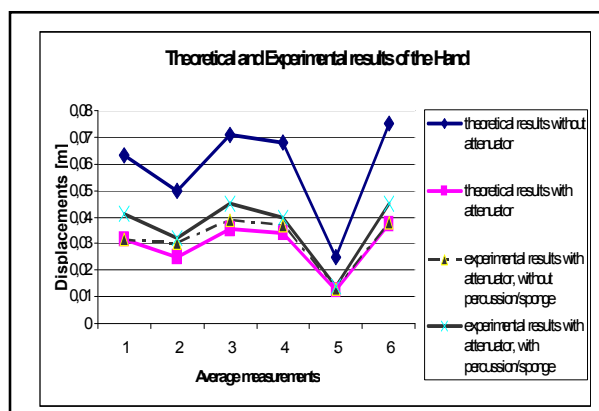

Fig. 13 Vibrations transmitted on the hand (theoretical and experimental) with and without sponge padded damper and using a drilling machine with and without percussion.

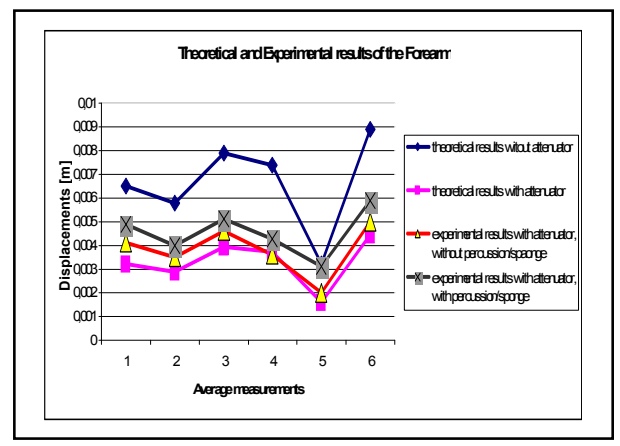

Fig. 14 Vibrations transmitted on the forearm (theoretical and experimental) with and without sponge padded damper, and using a drilling machine with and without percussion.

The results presented in figures 13,14 , and 15 have shown that, the vibrations transmitted to the hand-arm system are reduced from the hand up arm, by using the vibration attenuator device (starting from 0.005 till $0.002 \mathrm{~m}$ ) and especially when using the drilling machine without percussion. This analysis was also performed comparing the theoretical model with an attenuator device included in the model.

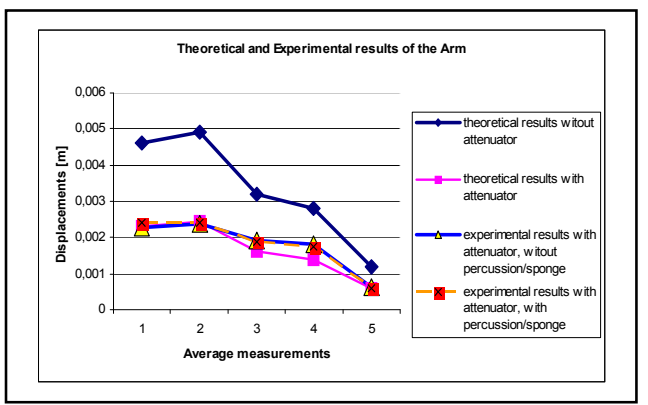

Fig. 15 Vibrations transmitted on the arm (theoretical and experimental), with and without sponge padded damper, and using a drilling machine with and without percussion.

The results presented in figures 16 and 17 show that, when using the drilling machine without and with percussion, with the same sponge padded bracelets, in both cases, the vibrations in the three anatomic locations (hand, forearm and arm) decrease (starting from 0.04 till $0.005 \mathrm{~m}$ ) in the first case (without percussion). However, the vibrations are felt harder in the hand in both cases (without and with percussion). In the case of the forearm and arm, the values do not present big differences (thousands place order), in any case lower in comparison to the case study - the felt padded bracelets.

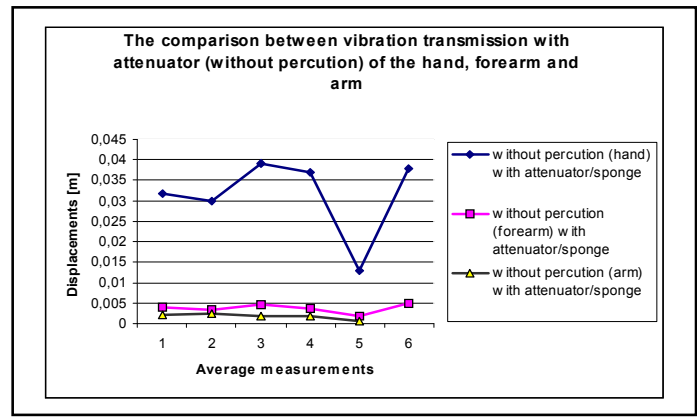

Fig. 16 Vibrations transmitted to the hand, forearm and arm using a vibration damper padded with sponge, and using a drilling machine without percussion.

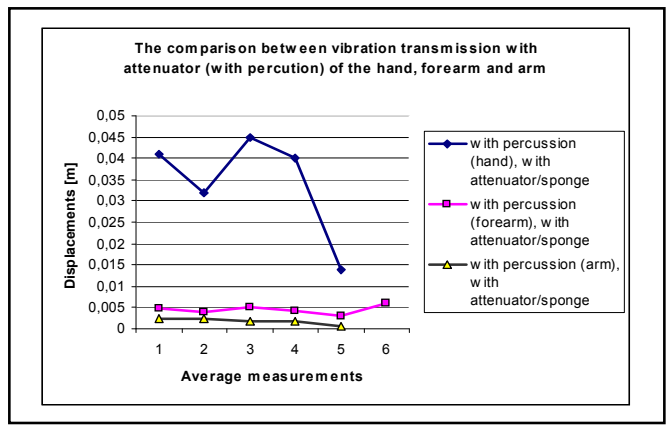

Fig. 17 Vibrations transmitted to the hand, forearm and arm using a vibration damper padded with sponge, and using a drilling machine with percussion. 
Figures $18 a$ and $b$ present the fastening methods for the attenuator device on the forearm and the interior padding of the bracelets with sponge and felt, and figure 19 presents the fastening elements (element 2 from figure 18b), between two vibration dampers (part of the device) mounted parallel on the worker's forearm.

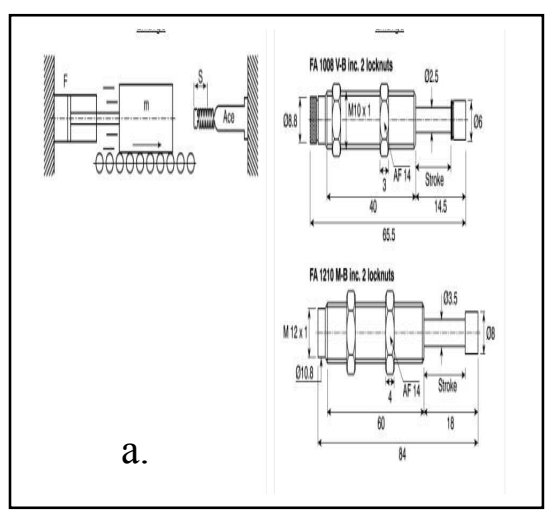



b.



c.

Fig. 18 Fastening the attenuator device on the forearm.

a. Technical characteristics of mini-attenuator FA 1008 VB (element 1 of figure 18b);

b. Interior padding with sponge;

c. Interior padding with felt.

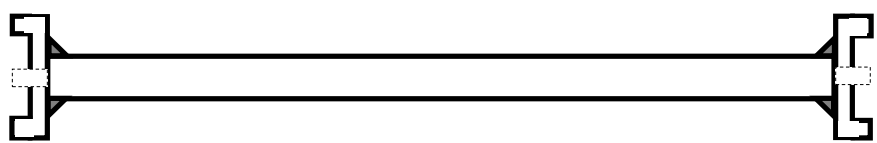

Fig. 19 Connecting element between the two vibration dampers that are part of the damper device.

\section{Conclusions}

The innovative idea of this paper was the experimental creation (design and realization of the practice) of a vibration attenuator device, which will be mounted along of the forearm; this could minimize the transmitted vibration, by the hand up the arm. Also, the purpose of the paper was to demonstrate that, the mechanical vibrations transmitted from an excitation source (ex. Machine-Tool) to the human operator (hand-arm system) are reduced from the hand to the elbow joint by mounting an attenuator device along the forearm [18,19]. All these studies were done in order to avoid or reduce the action of the vibrations on the human body (in this case the hand-arm system) at the workplace, and respectively the reduction of their effect and the prevention of occupational illnesses. The introduction of this paper mentions that occupational illnesses occur after years of vibration exposure, at the workplace. In order for the purpose of the paper to be reached, it developed a simulated model of a hand-arm system that would coincide as much as possible with a real one and it solved the equations of the simulated model. This is a system of dynamic differential equations, so solved it using order 4 Runge-Kutta (ODE45) of the Matlab program. Also, it could not solve the equations in the lack of the anthropometric input data (mass, length, etc.) and the rigidity and dampness coefficients $(k, c)$. It accomplished all this by means of three major steps:

a1. Creating a mechanical model and the analysis of the solutions (Fig. 3)

a2. Creating a Simulink model (Fig. 4 - without attenuator device, Fig. 5 - with attenuator device mounted on the forearm), that is created according to the theoretical model given by figure 3

a3. Performing experiments (vibration measurements) on the hand-arm system (Fig.18b,c and Fig. 8-16), which lead to the validation of the theoretical model and the results of the simulation.

The mini-dampers (case a3.) were purchased and mounted on the device and it tried to maintain the same technical characteristics as the theoretical model given by figure 3. The experiment, presented in this paper, was done using a drilling machine that functioned alternatively with and 
without percussion. The results were analyzed and were presented in figures 8,9 and 10 . They show that the mechanical vibrations generated by the machine-tool or device are reduced along the hand-arm system if:

1. An attenuator device is mounted along the forearm;

2. The operator uses a drilling machine without percussion;

3. The inner lining of the bracelets that are part of the attenuator device is made of sponge and not felt.

At the same time, the theoretical results have shown that, without this attenuator device $[1,5,19]$, the vibrations transmitted from the machine-tools (drilling machine) to the hand are higher, than the ones transmitted when such an attenuator device is mounted along the forearm. Irrespective of the fact, whether the drilling machine will work with or without percussion (Fig. 8-16). In this way, the vibrations are a reduced a lot from the hand (entry point of vibrations) to the arm with up to $50 \%$ [20-23].

At the same time, the vibrations along the forearm to the shoulder are reduced more, if the inner lining of the bracelets of the damper (element 2 in figure 18b) is made of a medium density sponge, than if the lining is made from other materials (felt in this case).

At this stage, since the ergonomic part of the device has not been established yet, these lining materials (sponge and/or felt) are necessary, otherwise, the metallic bracelets placed on the wrist and under the elbow might injure the skin. In addition, they prevent the device from slipping, allowing the operator to work with the machine - tool or to handle the device properly.

Wearing an attenuator device, like the one, presented in the paper, it has proven that (by simulation and experimental research):

1. It reduces the vibrations transmitted to the arm along the arm to the shoulder and could reduce the risk of occupational illnesses;

2. It restores the tactile comfort of the fingers and extra comfort when gripping tools and devices.

\section{Discussions}

This paper was focused only on the protective gear against the transmission of vibrations, to the hand-arm system which is being mounted on.

Occupational illnesses of the hand start by the loss of dexterity when handling working instruments and devices and they lead to the weakening of the grip of the fist and the weakening of the grip in the fingers accompanied by fatigue, etc. $[1,5,19]$. In time, all these symptoms can degenerate in occupational disorders, such as VWF and other professional illnesses (affecting the nervous and circulatory systems, spine, hearing and sight, etc.).

The literature shows that the protective means against mechanical vibration transmission at the workplace, with respect to the safety of the operator, it can be divided into two sub-categories:

a) Protective equipment, meaning protective clothing as safety means: for example overalls, boots, and gloves. The gloves are used to avoid or rather to dissipate (absorb) the vibrations from vibratory workplaces (for example mining, constructions, lathe working, etc.), vibrations that are transmitted from tools and machine - tools, directly to the hand of the human operator.

b) The second category refers to the protection or safety means, that are incorporated in tools and vibrating equipment from the design phase. These are called dampers and can take different shapes and dimensions and can be made from various materials.

Therefore, this paper is at the border between the two sub-categories presented in the literature, that is the attenuator device is not entirely safety equipment, by this referring to the equipment that can be worn. On the other hand, the attenuator device are not incorporated in any device or working tool, but they are rather mounted on the forearm, and they are closer to protective equipment that must be worn in order to reduce the mechanical vibrations transmitted through the hand to the hand-arm system.

- Further research in this field will contribute to the ergonomic and esthetic part of the new attenuator device; 
- At the same time, further research will analyze the effect of mini-dampers mounted in parallel to the forearm and it will compare the new experimental results with the ones obtained by mounting the same dampers in series (element 1), which has been the object of this paper (Fig. 3 and Fig. $18 b, c)$.

\section{Acknowledgement}

This paper was supported by the project "Development and support of multidisciplinary postdoctoral programmes in major technical areas of national strategy of Research - Development Innovation" 4D-POSTDOC, contract no. POSDRU / 89 / 1.5 / S / 52603, project co-funded by the European Social Fund through Sectoral Operational Programme Human Resources Development 2007-2013."

\section{References}

[1] K. T. Palmer, D. Coggon, H. E. NSyddall, et. al.: Occupational exposure to noise and hearing difficulties in Great Britain University of Southampton for Health and Safety Executive., Contract research report 361/2001, Great Britain, Southampton, ISBN 071762087-5, http://www.hse.sov.uk/research/crr-pdf/2001/crr01361.pdf, (2001), p. 1-70.

[2] M. J.Griffin: Hand-transmitted Vibration: Occupational Exposures and their Health Effects in Great Britain, 2001. University of Southampton, U.K. (1999).

[3] H. Mao, K. H. Yang, I. Albert, et. al. : Computational neurotrauma-design, simulation, and analysis of controlled cortical impact model, http://www.Springerlink.com, Received: 4 August 2009 / Accepted: 19 March 2010 / Published online: 7 April 2010 (C) The Author(s), 2010.

[4] B. Rong, X. Rui, G. Wang_et. al.: New efficient method for dynamic modeling and simulation of flexible multibody systems moving in plane. Multibody System Dynamics. 24: Number 2., DOI: 10.1007/s11044-010-9196-9, Biomech Model Mechanobiol (2010) 9:763-772, DOI 10.1007/s10237-010-0212-z, (2010), p. 181-200.

[5] A. Todea, A. Ferencz: Professional Morbidity in 2006 in Romania, Publish Health Institute, Work Medicine Institute, Bucharest, Romania, (2006).

[6] A. F. Pop, A. Truţa, M.Arghir: The mechanical stability for the hand-arm system. Vol.8. 1: 79th Annual Meeting of the International Association of Applied Mathematics and Mechanics (GAMM). Bremen. Germany, (2009), p. 10187-1018;

http://www3.interscience.wiley.com/journal/122217852/abstract?CRETRY=1\&SRETRY=0,

Article first PAMM published online: 25 FEB 2009, DOI: 10.1002/pamm.200810187, (2009).

[7] T. Cherian, S. Rakheja, R. B. Bhat: An analytical investigation of an energy flow divider to attenuate hand-transmitted vibration, Concordia University, Canada, (1996), p. 455-467.

[8] M. J. Griffin: Hand-transmitted Vibration: Occupational Exposures and their Health Effects in Great Britain, University of Southampton, U.K, (1999), p. 218-228.

[9] C. M. Harris, A. G. Piersol: Harris'Shock and Vibration Handbook, Columbia University, Fifth Edition, New York, ISBN 0-07-137081, (2002), p. 1.1-42.62.

[10] J. Awrejcewicz: Classical Mechanics. Dynamics. Springer, New York, http://www.amazon.com/s/ref=ntt_athr_dp_sr_1?_encoding=UTF8\&sort=relevancerank\&searchalias $=$ books\&ie $=$ UTF $8 \&$ field-author $=$ Jan\%20Awrejcewicz, $(2012)$.

[11] H. Haider, P.S. Walker: Measurements of Constraint of Total Knee Replacement. Public Health Resources. Paper 43, Journal of Biomechanics 38, (2002), p. 341-348;

http://digitalcommons.unl.edu/publichealthresources/43. DOI:10.1016/j.jbiomech.2004.02.014, (2002).

[12] G. Kostin, V. Saurin: The method of integro-differential relation for linear elasticity problems. Arch. Appl. Mech. 76 Springer. DOI 10.1007/S00419-006-0039-3, http://www.springerlink.com/content/91732586501kp800/fulltext.pdf, (2006), p. 391-402. 
[13] M. Kutz: Mechanical Engineers' Handbook, A Wiley-Interscience Publication John Wiley \&Sns.Inc, Second Edition. Canada. ISBN-0-471-13007-9, s\%20Handbook\%20 (www.eBookByte.com)\%20Ch-fm.pdf, (1998).

[14] H. Liu, P. J. Ellison, H. Xu, et al. : Coupling of dynamics and contact mechanics of artificial hip joints in a pendulum model. Proceedings of the Institution of Mechanical Engineers. Part H: Journal of Engineering in Medicine August 1, 224, DOI:10.1243/09544119JEIM687, (2010), p. 989-1003.

15] A. M. Sims, T. Stait-Gardner, L. Fong, et. al.: Elastic and viscoelastic properties of porcine subdermal fat using MRI and inverse FEA Biomech Model Mechanobiol. 9: DOI 10.1007/s10237-010-0207-9. Received: 17 November 2009 / Accepted: 4 March 2010 / Published online: 23 March 2010 C Springer-Verlag, (2009), p. 703-711.

[16] A. Galton, T. Duran: Memis-Mheg environment for multimedia information and simulation. University of Strathclyde, Glasgow, U. K. 6: (1998), p. 3813-3816.

[17] P. J. Gyu: Vibration simulation using Matlab, Department of Precision Engineering. Kyoto University. Japan, http://wenku.baidu.com/view/a02c33d5b9f3f90f76c61b29.html.,(2008),p.182.

[18] J. H. .Jacobs: Miniature vibration isolation system, Aerospace Conference Proceedings IEEE. USA. vol. 4, ISBN-0-7803-5846-5, (1998), p. 335-344.

[19] P. Urban, E. Lukas: Occupational diseases due to hand-arm vibration in the Czech Republic in the year. The Eight International Conference on Hand-Arm Vibration. Umeå. Sweden., (1997), p. 153-155.

[20] SREN 5349-2:2003: Mechanical Vibrations.Measurements and evaluation of human exposure at vibrations transmitted of hand.

[21] SRCR 10 30-2:2000: Hand-arm vibrations. Indications for reduce vibration risk. Part 2: the measure of prevention regarding the working place.

[22] SR ISO 7962:1996: Mechanical vibrations. Transmissibility of mechanical vibrations of human body after $\mathrm{z}$ direction.

[23] SR ISO 8727:2001: Mechanical vibrations and shocks. Human exposure, biodynamical system coordinates. 